\title{
Inheritance of allozymes from seed tissues of the hexaploid gymnosperm, Sequoia sempervirens (D. Don) Endl. (Coast redwood)
}

\author{
DEBORAH L. ROGERS \\ Pacific Southwest Research Station, USDA Forest Service, PO Box 245, Berkeley, CA 94701, U.S.A.
}

\begin{abstract}
Coast redwood, Sequoia sempervirens, is a hexaploid gymnosperm of putative autoallopolyploid origin. In this first study of allozymes from the seed tissues of Coast redwood, six enzyme systems were examined in the megagametophyte and embryo tissues of nine control-pollinated (full-sib) families. Megagametophyte segregation patterns reflected considerable within-family segregation and a meiotic process that is consistent with hexasomic segregation. The array of gametic phenotypes observed precludes strictly disomic segregation. Staining intensity of banding patterns was an unreliable indicator of allozyme frequency, and scoring of phenotypes in this study was conducted conservatively. Observations do not refute the long-standing hypothesis of an autoallopolyploid origin.
\end{abstract}

Keywords: allozymes, Coast redwood, inheritance, polyploid, Sequoia sempervirens.

\section{Introduction}

Polyploidy is of major importance in the evolution of plants. A conservative estimate for the percentage of angiosperm species of polyploid origin is near 30 per cent and for pteridophytes over 40 per cent (Werth, 1989), although polyploid gymnosperms are less common. Coast redwood, Sequoia sempervirens (D. Don) Endl., a hexaploid of putative autoallopolyploid origin, is one of only three extant coniferous polyploids. Although the population genetic consequences of polyploid inheritance are considerable (e.g. Moody et al., 1993), these species are generally under-represented in the genetics literature.

Isozymes have been widely used to study genetic structure in natural populations, estimate parameters of mating systems, assist in plant breeding efforts, provide evidence of filial relationships and study evolutionary processes. To use allozymes effectively in genetic studies, knowledge of their inheritance is a prerequisite. This information is perhaps most easily gained in conifers where the megagametophyte of a mature seed expresses the maternal (haploid) contribution to the embryo and therefore permits the use of open-pollinated seed in

${ }^{*}$ Correspondence. $\quad$ E-mail: $\quad \mathrm{fswa} / \mathrm{s}=\mathrm{d}$.rogers $/ \mathrm{ou}=\mathrm{S} 27 \mathrm{a} @ \mathrm{mhs}$. attmail.com inheritance studies. In nonconifers, the genetic bases of enzyme phenotypes can only be established by producing pedigreed material and analysing the allozyme patterns among known relatives. Furthermore, assumptions of Mendelian inheritance are largely justified if congeneric species have been previously studied and shown to exhibit Mendelian inheritance of the same isozymes.

The origin of polyploidy in Coast redwood has never been confirmed. Stebbins (1948) provided evidence for a haploid number of 33 taken from two different chromosome groups at first anaphase. Later karyotype studies (e.g. Fozdar \& Libby, 1968; Saylor \& Simons, 1970) confirmed that $2 n=6 \mathrm{x}=66$ for this species. The most comprehensive karyotype data, those of Saylor \& Simons (1970), support most strongly an autoalloploid origin - one of two possibilities suggested by Stebbins in 1948. An analysis of allozyme patterns may help determine the nature of polyploidy in this enigmatic species with its unusual suite of traits including hexaploidy, longevity, woodiness and clonality.

In the case of $S$. sempervirens, its hexaploid genetic system complicates the investigation of allozyme inheritance. It has no (extant) congeneric relatives and its closest relatives are diploid (i.e. $2 n=2 \mathrm{x}=22$ ) and thus contribute little to our expectations of isozyme behaviour in this species. Therefore, an inheritance study of Coast redwood 
isozymes is imperative for a reliable genetic interpretation of isozyme-based studies. Of the several Mendelian segregation models possible with a hexaploid species, only one model - that of hexasomic chromosomal segregation - was investigated here because of data limitations.

The objectives of this study are: (i) to investigate the inheritance of allozymes in the only hexaploid conifer; (ii) to test the usefulness of isozymes for genetic analyses of Coast redwood; and (iii) to inspect the number of loci and segregation patterns for evidence supporting an allo- or autopolyploid model of species origin.

\section{Materials and methods}

\section{Seed source}

Seeds from nine control-pollinated (full-sib) families were provided by the Tree Improvement Program of the Simpson Timber Company of Arcata, CA. Parental trees had been selected from natural redwood stands over a wide area of the company's 400000 acre estate in northern California and established via scions in a seed orchard. Two of the nine families were produced using the same female parent; all other families were unrelated.

\section{Germination methods}

Seeds were soaked in an aerated water bath for $24 \mathrm{~h}$ and then stratified at $4^{\circ} \mathrm{C}$ for approximately three weeks. Upon returning the seeds to room temperature, germination commenced within five to nine days. Redwood seeds may show considerable specific combining ability, as illustrated by the highly variable germination rates observed among full-sib, control-pollinated, families (Lewis, 1992; M. Diegan, Simpson Timber Company, pers. comm., Nov., 1994). Seeds from families 1,2 and 3 were unsorted. Seeds from the remaining six families were sorted (by winnowing) prior to germination, thereby removing some of the lighter (and probably unfilled or aborted) seeds, and thus improving the expected germination rate. Germination rates, by family, varied from 47 to 96 per cent, well above rates that have been reported for unsorted wild collections (e.g. 2.5 per cent to 12.4 per cent, Boe, 1965; < 15 per cent, Olson et al., 1990).

The selective use of germinants and their megagametophytes implies that there was not a random sampling of meiotic products. Inviable haplotypes or unsuccessful hexaploid combinations were not included. Six of the nine families were sorted, thereby probably removing some filled but light seeds. Thus, there was some selection, resulting both from the use of megagametophyte-embryo pairs and from sorting. The amount and effect of such selection are unknown but are unlikely to introduce a large bias into the study. Also, there were modest controls for the effects of both sorting (i.e. three unsorted families) and germination (i.e. family 4 had almost 100 per cent germination). An earlier study of selfed and related outcrossed families of Coast redwood suggests that selfing in this species produces little evidence of inbreeding depression in seed production and germination (Libby et al., 1981).

After the germinating radicle had extended a few millimetres beyond the seed coat, the embryo was excised so that the megagametophyte and embryo tissues could be analysed separately. Both kinds of seed tissues were then each macerated in a few drops of a $0.5 \mathrm{~m}$ phosphate buffer $(\mathrm{pH} 7.5)$ modified with the addition of bovine serum albumin, dithiothreitol and potassium phosphate (Rogers, 1994). Samples from the embryo and megagametophyte tissues from each seed were placed on the same gel allowing ease of comparison of the allozymes in these two tissue types.

\section{Isozyme analysis}

Four buffer systems and 20 enzyme systems were assayed (Rogers, 1994). Six enzyme systems, including 12 putative isozyme loci in total, were selected for use in the inheritance study (Table 1). All were run on the morpholine citrate pH 8.1 buffer system. The selection was based on the consistent and scorable zymograms achieved with these enzyme systems. The electrophoretic buffer systems were prepared following the recipes provided in Conkle et al. (1982). The staining solutions used for the visualization of enzyme activities in the gels followed those of Wendel \& Weeden (1989).

The number of seeds assayed per family varied from 24 to 32, depending upon seed availability and germination success. For each enzyme system, the most anodal isozyme locus was designated as one, the next two, and so on. Allozymes within enzyme systems were designated on the basis of their migration distance relative to the most common allele of the most anodal locus, which was assigned the distance of 1.00 .

For the study reported in this paper, the megagametophyte tissues of Coast redwood were assumed to be triploid $(n=3 \mathrm{x})$ (Saylor \& Simons, 1970). Thus, if a megagametophyte contained one or 
Table 1 Enzymes assayed from Coast redwood seed, their Enzyme Commission (EC) reference numbers and description

No. of polymorphic

\begin{tabular}{|c|c|c|c|c|}
\hline Enzyme name & Abbreviation & EC no.* & Structure & loci scored \\
\hline \multicolumn{5}{|l|}{ Oxidoreductases } \\
\hline Isocitrate dehydrogenase $\dagger$ & Idh & 1.1.1.42 & Dimer & 1 \\
\hline Malate dehydrogenase & Mdh & 1.1.1.37 & Dimer & 3 \\
\hline 6-Phosphogluconate dehydrogenase & 6Pgd & 1.1.1.44 & Dimer & 2 \\
\hline Shikimate dehydrogenase & Skd & 1.1.1.25 & Monomer & 2 \\
\hline \multicolumn{5}{|l|}{ Isomerases } \\
\hline Phosphoglucoisomerase & Pgi & 5.3.1.9 & Dimer & 2 \\
\hline \multicolumn{5}{|l|}{ Phosphorylases } \\
\hline UDP-glucose pyrophosphorylase & Ugp & 2.7 .7 .9 & Monomer & $1 \ddagger$ \\
\hline
\end{tabular}

*Wendel and Weeden (1989).

$\dagger$ NADP-dependent.

$\ddagger$ A second locus was monomorphic.

two alleles at a locus, it would therefore contain three or two copies, respectively, of one of the alleles (e.g. 111,$222 ; 112,122)$. In some cases, megagametophytes were scored for both allele presence and dosage to investigate whether allele dosage could be reliably detected by relative staining intensity. The inferred maternal genotypes and the phenotypic classes of progeny were used to judge the accuracy of the staining intensity assumption. Ultimately, staining intensity could not be used to detect allelic dosage reliably in this study. Consideration of allele dosage is not necessary to differentiate between hexasomic and disomic segregation.

For each family and isozyme locus, megagametophytes were scored and grouped according to banding phenotype. The genotype of the female was inferred from the megagametophyte phenotypes. The lowest number of megagametophytes scored for any isozyme locus for any family was seven; the chance of not encountering an allozyme present in the female in this case is one in 128 (i.e. $0.5^{7}$ ). Embryo tissues were scored and compared with megagametophyte contributions for relative migration distances of allozyme bands and for the presence of additional bands contributed by the male.

In diploid gymnosperms, isozyme phenotypes corresponding to allelic variants are expected to occur in a 1:1 ratio among the haploid megagametophytes of heterozygous parents under a model of random segregation. In a hexaploid species, the expected frequency distributions of gametophytic phenotypic classes depend heavily upon the nature of the polyploidy and mode of segregation of homologous chromosomes during meiosis. Segregation analysis is further complicated if, as is the case in this study, gene dosage is not discernible in the triploid $(n=3 \mathrm{x})$ megagametophytes (i.e. where a 112 gametophyte is phenotypically indistinguishable from a 122 gametophyte).

Under the assumption that the reduction from $6 \mathrm{x}$ to $3 \mathrm{x}$ involves completely random segregation of homologous chromosomes, the inability to distinguish gene dosages can be dealt with by using combinatorial analysis to calculate the probability that a particular allele will not be included in a megagametophyte, given that there are one, two, three, etc. copies in the maternal parent. For example, if the maternal parent carries one copy of an allele, there is a probability of 0.50 that it will be excluded from any particular megagametophyte (Table 2). These allelic probabilities are easily expanded to obtain expected frequencies for the phenotypic classes of megagametophytes. For example, if the maternal genotype had three copies each of two alleles (e.g. 111222), one would expect gametophytic phenotypes of 111,222 and 12- in the relative frequencies of $1: 1: 18$, respectively (with the assumption of hexasomic chromosomal segregation). In this example, it has been assumed that the six heterozygous possibilities $(112,121,211,122,212$, 221 - differing by allele dosage and/or chromosome position) cannot be distinguished from one another and are grouped into a single synthetic class.

Megagametophyte phenotypes and their expected relative frequencies under hexasomic segregation were calculated for two-, three- and four-allele maternal genotypes (four being the highest number of allozymes observed for any locus of any female parent scored in the study; Table 3). 
Alternatively, consider the expectations under another model - that of disomic segregation. In this case, a maternal genotype of $112 / 122$ (NB same alleles and dosages, but different assumptions from the model discussed above) would be expected to produce only two genotypic classes of megagametophytes (112 and 122) in equal proportions. Further, because these two classes differ only in allelic dosage, for the purposes of this study the two classes would be indistinguishable (i.e. 12-).

Under the assumption of hexasomic segregation of six homologous chromosomes during meiosis, expected and observed phenotypic classes of megagametophytes were compared for each family using a chi-square test. The conventional probability $(P<0.05)$ was chosen to distinguish significant departures from expected segregation ratios.

\section{Results}

\section{Megagametophyte phenotypes}

Among the seed families assayed, 11 of the 12 isozyme loci studied were polymorphic, with two to four alleles per locus (Fig. 1). Comparisons were made between each megagametophyte and the corresponding embryo dissected from the same seed.

Table 2 The relationship between the number of copies of a given allele in the maternal parent and the probability that it will be excluded in any of its megagametophytes under the assumption of hexasomic (chromosomal) segregation*

\begin{tabular}{lcc}
\hline $\begin{array}{l}\text { No. of copies } \\
\text { of allele (e.g. 2) } \\
\text { in maternal parent }\end{array}$ & $\begin{array}{c}\text { Hypothetical } \\
\text { maternal } \\
\text { genotype }\end{array}$ & $\begin{array}{c}\text { Probability of allele 2 } \\
\text { being excluded from any } \\
\text { given megagametophyte }\end{array}$ \\
\hline 0 & 111111 & 1 \\
1 & 111112 & 0.50 \\
2 & 111122 & 0.20 \\
3 & 111222 & 0.05 \\
$\geq 4$ & 112222 , etc. & 0 \\
\hline
\end{tabular}

*An approach based on exclusion, rather than inclusion, is unambiguous. With the former, we need not be concerned with the number of copies of each allele in the megagametophyte, but only with its complete absence. The maximum probability of exclusion is based on completely randomized or hexasomic chromosomal segregation (i.e. randomly drawing three alleles from six). For each allele in the maternal parent, the table above is consulted and a probability obtained for the megagametophyte phenotypic class(es) in which that allele is absent.
Staining intensity was often darker for the (haploid) megagametophyte tissue. Relative mobilities of alleles were similar in both tissue types. Embryo tissue samples frequently showed additional bands to those scored in the megagametophyte, indicating the paternal contribution, and any bands present in the megagametophyte were also present in the corresponding embryo.

Shikimate dehydrogenase (Skd) Two zones of activity were observed on gels stained for Skd. This is consistent with reports for many conifers, although Xie et al. (1991) observed three zones of activity for Skd in Thuja orientalis, as did Millar (1985) in Pinus muricata. The quaternary structure of both isozymes in the present study is monomeric. Both isozymes were polymorphic in the redwood crosses. Skd-1 exhibited more alleles than Skd-2. Both Skd isozymes were faint and poorly resolved relative to the other isozymes studied. In addition, double-banded phenotypes, behaving as single alleles and scored as such, were common at both isozyme loci. Such behaviour in Skd has been previously reported (e.g. Harry, 1986).

Isocitrate dehydrogenase (Idh) Only one isozyme locus was observed in this study, although two Idh loci have been identified in some members of Cupressaceae (Harry, 1986; Perry \& Knowles, 1989; Xie et al., 1991) and as many as four loci have been reported in some plant species (e.g. Godt \& Hamrick, 1993). One-, three- and five-band patterns in the megagametophytes suggest that Idh is functionally dimeric in $S$. sempervirens, as has been reported in other conifers (e.g. El-Kassaby et al., 1982; Muona et al., 1987; Xie et al., 1991).

UDP-glucose pyrophosphorylase (Ugp) This enzyme system has been studied in several pine species and reported as having as many as five loci (Strauss \& Conkle, 1986). In the present study, two additional loci - corresponding with the 6Pgd enzyme system - were apparent on the Ugp zymograms (D. Delany, Institute of Forest Genetics, USDA Forest Service, Albany CA., pers. comm., 1993). It is probable that some of the previously reported Ugp isozymes are actually $6 \mathrm{Pgd}$, as was pointed out by Strauss \& Conkle (1986). Although two loci were observed for this enzyme, only the more anodal one was analysed as the other was monomorphic for the families involved in the present study. Banding patterns suggested that Ugp-1 is monomeric in quaternary structure. 
Table 3 Models of segregation patterns for megagametophyte phenotypes under the assumption of hexasomic segregation

I. Two-allele systems $(1,2)$

Expected megagametophyte phenotypic ratio

No. Maternal genotype $111 \quad 12-222$

\begin{tabular}{llrrr}
\hline$(1)$ & 111111 & 1 & & \\
$(3)$ & 111112 & 1 & 1 & \\
$(4)$ & 111122 & 1 & 4 & \\
& 111222 & 1 & 18 & 1 \\
\hline
\end{tabular}

II. Three-allele systems $(1,2,3)$

Expected megagametophyte phenotypic ratio

No. Maternal genotype $111 \quad 12-\quad 13-\quad 23-123$

\begin{tabular}{lllllll}
\hline$(5)$ & 112233 & & 1 & 1 & 1 & 2 \\
$(6)$ & 111223 & 1 & 9 & 3 & 1 & 6 \\
$(7)$ & 111123 & 2 & 3 & 3 & & 2 \\
\hline
\end{tabular}

III. Four-allele system observed in this study (122344)

Expected megagametophyte phenotypic ratio

\begin{tabular}{ccccccccccc} 
No. & Maternal genotype & 134 & 344 & 122 & 144 & 123 & 124 & 234 & 223 & $24-$ \\
\hline$(8)$ & 122344 & 2 & 1 & 1 & 1 & 2 & 4 & 4 & 1 & 4 \\
\hline
\end{tabular}

Phosphoglucoisomerase (Pgi) Two zones of activity were observed on gels stained for Pgi, as commonly observed in many other conifers (Neale \& Adams, 1981; Harry, 1986; Strauss \& Conkle, 1986; Xie et al., 1991), although three loci have been observed in some plant species, for example, Tradescantia hirsuticaulis (Godt \& Hamrick, 1993). Banding patterns observed suggest that both isozymes are functionally dimeric. Further, alleles of Pgi-2 tend to have migration distances that are simple multiples of one another, thus requiring care when scoring samples. For example, the allele designated as 2 lies in the same position as the middle band of the phenotype of a $1-3$ heterozygote.

Malate dehydrogenase (Mdh) This enzyme system consisted of three dimeric isozymes, with some overlap in alleles of the two faster-migrating isozymes. As many as four loci and a modifying locus have been previously identified in some pine species (e.g. Strauss \& Conkle, 1986). As such, the interpretation offered here is tentative, and not exclusive of other possible interpretations. A locus with bands anodal to $M d h-1$ was faintly present in the embryo, but not megagametophyte, tissues of Coast redwood.
6-Phosphogluconate dehydrogenase (6Pgd) Two zones of activity, suggesting two loci, were observed on zymograms stained for 6Pgd. Three- and fivebanded isozyme phenotypes of heterozygous megagametophytes suggested iilai 6Pgd is functionally dimeric for both isozymes in $S$. sempervirens, as reported in many other conifers (e.g. El-Kassaby et al., 1982; Perry \& Knowles, 1989; Xie et al., 1991). The resolution of $6 P g d-2$ was much better for megagametophyte than embryo tissue.

\section{Inheritance of isozyme variants}

Examples from the segregation analyses are presented in Table 4. (Specifically, results for $S k d-2$, Pgi-1, Mdh-1 and $M d h-3$ are not shown because of the high incidence of monomorphism at these loci.) Of the 53 chi-square tests performed on segregating loci (46 of which are shown), most segregation data conformed to hexasomic expectations. Some tests were performed on small sample sizes and may not be reliable. Significant deviations from expectations were observed for seven ratios using the conventional probability of $P<0.05$. However, for this number of tests, several 'significant' departures

(C) The Genetical Society of Great Britain, Heredity, 78, 166-175. 
(a)

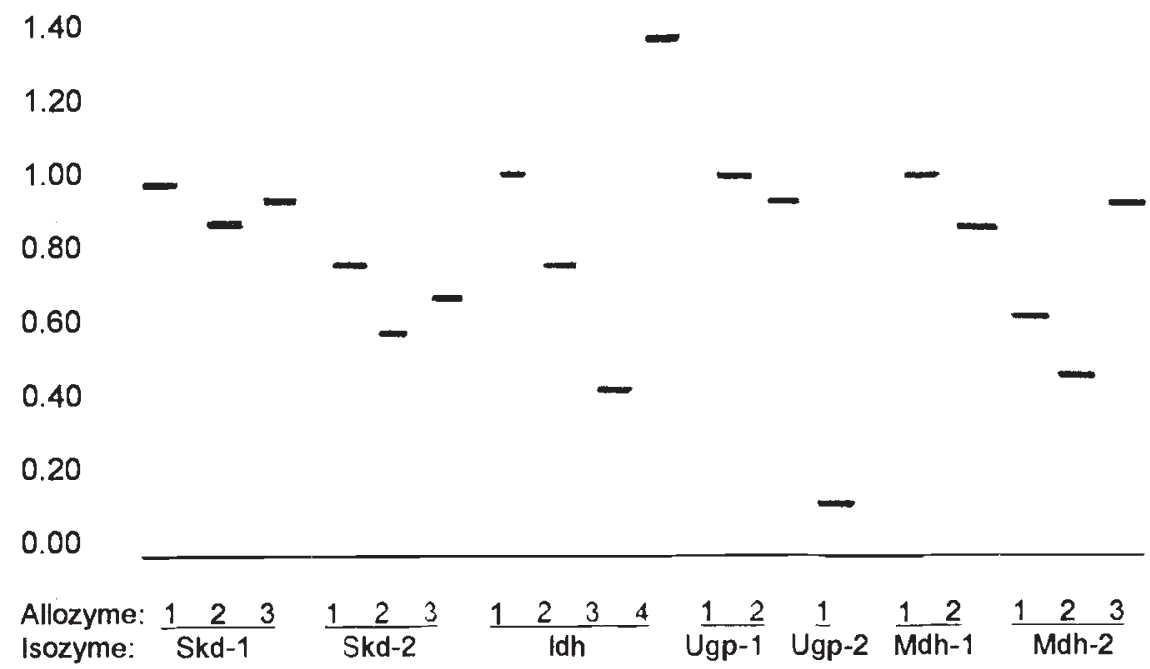

(b)

Fig. 1 Allozyme phenotypes for the 12 isozymes observed in seeds of Coast redwood (Sequoia sempervirens).

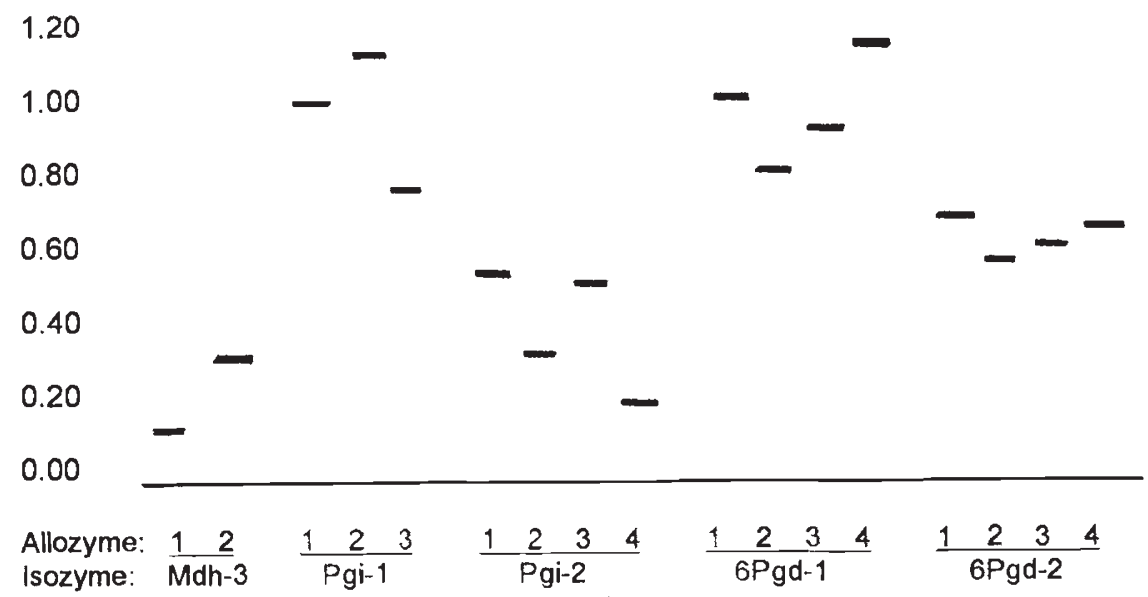

could be expected on the basis of chance alone. The six deviations were not consistent with disomic segregation either.

Although two families (cross numbers 1 and 3 ) had the same maternal parent, and therefore could be pooled for the purposes of estimating segregation ratios, the data were kept separate by family as a preliminary test for postzygotic selection (i.e. postzygotic selection is one cause of distorted segregation ratios; it is caused when certain pollen-egg combinations are less viable than others, thus providing selection pressure against certain megagametophytes). Megagametophyte segregation patterns for this female met expectations (under the model of hexasomic segregation) in all but one case where data were available (6Pgd-1). This one devia- tion from expectations could have been caused by chance alone rather than constituting evidence of segregation distortion.

\section{Allele dosage within individuals}

Several lines of evidence suggested that staining intensity was an unreliable indicator of allele dosage within an individual megagametophyte or embryo. First, staining intensity varied greatly among megagametophytes from the same monomorphic female (Fig. 2). Three doses of the same allele varied from very faintly staining to very darkly staining. Secondly, embryos sometimes showed staining that was inconsistent with inferred composition (see example explained in Fig. 2). In the attempts 
Table 4 Examples of phenotypic segregation for two, three and four alleles, in megagametophytes of nine crosses (using eight maternal parents) of Sequoia sempervirens

\begin{tabular}{|c|c|c|c|c|c|}
\hline Locus & $\begin{array}{c}\text { Cross } \\
\text { no. }\end{array}$ & $\begin{array}{l}\text { Maternal } \\
\text { genotype* }\end{array}$ & $\begin{array}{l}\text { Observed (and expected) } \\
\text { megagametophyte } \\
\text { segregation ratios } ¥\end{array}$ & $\chi^{2}$ & $P$ \\
\hline$S k d-1$ & $\begin{array}{l}1 \\
2 \\
3 \\
4 \\
5 \\
6 \\
7 \\
8 \\
9\end{array}$ & $\begin{array}{l}111111 \\
111222 \\
111111 \\
111111 \\
111333 \\
122333 \\
111223 \\
111222 \\
222213\end{array}$ & $\begin{array}{l}24(1) \\
3: 14: 5(4) \\
24(1) \\
32(1) \\
2: 9: 1(4) \\
1: 9: 4: 1: 5(6) \\
2: 9: 4: 0: 6(6) \\
4: 20: 3(4) \\
4: 7: 10: 7(7)\end{array}$ & $\begin{array}{l}\overline{18.8} \\
\overline{-} \\
\overline{3} .99 \\
0.50 \\
2.17 \\
7.98 \\
1.34\end{array}$ & $\begin{aligned} & 1.00 \\
\cong & 1.00 \\
& 1.00 \\
> & 0.10 \\
> & 0.95 \\
> & 0.50 \\
> & 0.01 \\
> & 0.50\end{aligned}$ \\
\hline$I d h$ & $\begin{array}{l}1 \\
2 \\
3 \\
4 \\
5 \\
6 \\
7 \\
8 \\
9\end{array}$ & $\begin{array}{l}111111 \\
111112 \\
111111 \\
111112 \\
111112 \\
111112 \\
111111 \\
111112 \\
111224\end{array}$ & $\begin{array}{l}24(1) \\
13: 11(2) \\
24(1) \\
16: 15(2) \\
16: 15(2) \\
18: 13(2) \\
32(1) \\
18: 14(2) \\
2: 16: 3: 1: 9(6)\end{array}$ & $\begin{array}{l}\overline{0.17} \\
\overline{0.03} \\
0.03 \\
0.80 \\
\overline{0.44} \\
1.23\end{array}$ & $\begin{array}{r}1.00 \\
>0.50 \\
1.00 \\
>0.75 \\
>0.75 \\
>0.25 \\
1.00 \\
>0.50 \\
>0.75\end{array}$ \\
\hline$U g p-1$ & $\begin{array}{l}1 \\
2 \\
3 \\
4 \\
5 \\
6 \\
7 \\
8 \\
9\end{array}$ & $\begin{array}{l}111111 \\
111112 \\
111111 \\
111112 \\
111122 \\
\text { NA } \\
111111 \\
111111 \\
111222\end{array}$ & $\begin{array}{l}24(1) \\
10: 14(2) \\
24(1) \\
11: 13(2) \\
2: 14(3) \\
\overline{16}(1) \\
16(1) \\
1: 14: 1(4)\end{array}$ & $\begin{array}{l}\overline{0.67} \\
\overline{0.17} \\
0.76 \\
\overline{-} \\
\overline{0}\end{array}$ & $\begin{array}{r}1.00 \\
>0.25 \\
1.00 \\
>0.50 \\
0.25 \\
- \\
1.00 \\
1.00 \\
>0.90\end{array}$ \\
\hline Pgi-2 & $\begin{array}{l}1 \\
2 \\
3 \\
4 \\
5 \\
6 \\
7 \\
8 \\
9\end{array}$ & $\begin{array}{c}112223 \\
122333 \\
112223 \\
\text { NA } \\
222224 \\
\text { NA } \\
112244 \\
112224 \\
122222\end{array}$ & $\begin{array}{l}2: 10: 5: 3: 4(6) \\
2: 6: 1: 1: 1(6) \\
2: 11: 3: 3: 3(6) \\
- \\
6: 9(2) \\
-4: 2: 3: 6(5) \\
2: 5: 3: 2: 4(6) \\
9: 6(2)\end{array}$ & $\begin{array}{l}5.25 \\
6.27 \\
6.13 \\
- \\
0.60 \\
- \\
0.66 \\
4.55 \\
0.60\end{array}$ & $\begin{array}{l}>0.25 \\
>0.10 \\
>0.25 \\
\overline{-} \\
>0.25 \\
>0.75 \\
>0.25 \\
>0.25\end{array}$ \\
\hline$M d h-2$ & $\begin{array}{l}1 \\
2 \\
3 \\
4 \\
5 \\
6 \\
7 \\
8 \\
9\end{array}$ & $\begin{array}{l}111123 \\
111111 \\
111123 \\
111333 \\
111113 \\
111222 \\
111112 \\
111123 \\
111122\end{array}$ & $\begin{array}{l}7: 17(7) \\
24(1) \\
5: 6: 9: 4(7) \\
2: 24: 4(4) \\
14: 17(2) \\
3: 3: 24(4) \\
8: 8(2) \\
4: 14: 8: 6(7) \\
7: 25(3)\end{array}$ & $\begin{array}{c}14.35 \\
-\overline{0.79} \\
4.67 \\
0.29 \\
3.33 \\
0 \\
3.22 \\
0.07\end{array}$ & $\begin{aligned} \cong & 0 \\
& 1.00 \\
> & 0.75 \\
> & 0.05 \\
> & 0.50 \\
> & 0.10 \\
& 1.0 \\
> & 0.25 \\
> & 0.75\end{aligned}$ \\
\hline $6 P g d-1$ & $\begin{array}{l}1 \\
2 \\
3 \\
4 \\
5 \\
6 \\
7 \\
8 \\
9\end{array}$ & $\begin{array}{c}122233 \\
112222 \\
122233 \\
111224 \\
112224 \\
124444 \\
122334 \dagger \\
112233 \\
11123\end{array}$ & $\begin{array}{l}0: 7: 5: 6: 6(6) \\
8: 21(3) \\
3: 7: 2: 4: 8(6) \\
4: 12: 2: 4: 4(6) \\
0: 14: 4: 3: 5(6) \\
8: 8: 6: 6(7) \\
1: 0: 2: 0: 2: 3: 2: 2: 3(8) \\
9: 4: 7: 11(5) \\
8: 7: 9: 6(7)\end{array}$ & $\begin{array}{r}22.48 \\
1.04 \\
11.37 \\
13.99 \\
4.97 \\
1.76 \\
1.74 \\
2.17 \\
1.33\end{array}$ & $\begin{array}{l}\cong 0 \\
>0.25 \\
>0.01 \\
<0.01 \\
>0.25 \\
>0.50 \\
>0.95 \\
>0.50 \\
>0.50\end{array}$ \\
\hline
\end{tabular}


Table 4 Continued

\begin{tabular}{lcclcc}
\hline Locus & $\begin{array}{c}\text { Cross } \\
\text { no. }\end{array}$ & $\begin{array}{c}\text { Maternal } \\
\text { genotype* }\end{array}$ & $\begin{array}{l}\text { Observed (and expected) } \\
\text { megagametophyte } \\
\text { segregation ratios }\end{array}$ & $\chi^{2}$ & $P$ \\
\hline 6 6gd-2 & 1 & 112222 & $5: 16(3)$ & 0.38 & $>0.75$ \\
& 2 & 111233 & $6: 10: 6: 3: 3(6)$ & - & - \\
& 3 & NA & - & - & - \\
& 4 & NA & - & - & - \\
& 5 & NA & - & 9.15 & $>0.05$ \\
& 6 & 111224 & $0: 15: 1: 4: 8(6)$ & 0.11 & $>0.90$ \\
& 7 & 111222 & $1: 14: 1(4)$ & 3.93 & $>0.25$ \\
& 8 & 111224 & $2: 12: 3: 3: 5(6)$ & 4.64 & $>0.05$ \\
\hline
\end{tabular}

*Inferred maternal genotype, based on megagametophyte phenotypes. †Yates' correction for continuity was applied because of small class size. \$Expected megagametophyte segregation ratio is based on an assumption of hexasomic (chromosomal) segregation. Observed phenotypic classes are presented in the same order as they appear for the appropriate model in Table 3 (the latter is indicated in parentheses).

Fig. 2 Staining patterns for $I d h$ for one seed family of Coast redwood (Sequoia sempervirens). Red pine (Pinus resinosa) markers occur at the first, mid (i.e. 14th) and final columns of the gel. The first 12 redwood entries are megagametophytes; the second 12 , corresponding embryos within the full-sib family. The female is apparently homozygous (allele 1) for this dimeric locus. The male is heterozygous, containing at least three doses of allele 1 (as evidenced by the homozygous embryos) and two additional alleles in the upper gel (alleles 2 and 3). As an example of staining intensity that is inconsistent with inferred allele dosage, note the second from last embryo (the 11th embryo). The embryo genotype in this case is either 111112 or 111122 (depending on whether the male is 111123 or 111223). Although the allelic dosage is unbalanced, bands 1 and 2 and the intermediate band have similar staining intensity.

to score megagametophytes according to allele dosage there were cases recorded at every isozyme locus in every family in which the dosage interpretations were inconsistent with possible segregation ratios.

\section{Discussion}

Although the objectives of this study are concerned with inheritance, as this is the first allozyme study of $S$. sempervirens it is also appropriate to comment on the allozyme diversity observed. Genetic diversity was very high as measured by percentage of loci polymorphic ( 92 per cent). The mean number of alleles per locus observed (2.8) is among the higher values noted for western North American conifer species (Millar \& Marshall, 1991). This value for genetic diversity in Coast redwood may be a conservative estimate as the materials in this study reflect only local and not range-wide allozyme variation in the species.

As null phenotypes were not observed, this suggests that nulls were not common enough to occur as null homozygotes. Perhaps this is not surprising, as a null phenotype would require the presence of three null alleles (in the megagametophyte; six in the embryo). However, although nulls were not observed in this study, some have predicted 
that nulls are more likely in polyploids than in diploids (Weeden \& Wendel, 1989).

The six enzyme systems studied in seed tissues of $S$. sempervirens appear to be encoded by 12 isozyme loci, 11 of which are polymorphic in the nine-family sample. Analysis of megagametophyte composition portrays considerable within-family segregation and a pattern largely consistent with hexasomic inheritance for the loci analysed in seed tissues. Comparisons of megagametophyte and embryo phenotypes did not disclose any anomalies that would cast doubt on the validity of embryo banding patterns as being the product of male and female contributions. The results are consistent with the use of isozyme analysis in seed tissues, at least for the 12 isozyme loci fully studied here, in other genetic studies of the species.

Results suggest that, in this species, putative allozymes should be confirmed with inheritance studies because of the existence of overlapping loci and double-banded allozymes. Further, the use of staining intensity as an indicator of allele dosage is not supported by this study. In this inheritance study of Coast redwood, tissues were conservatively scored to reflect presence, but not dosage, of alleles. Other isozyme studies of polyploid plant species have used staining intensity as a direct and quantitative measure of allele dosage: few, however, actually tested the validity of the procedure with inheritance studies. A convincing demonstration of the lack of correspondence between staining intensity and allozyme dosage was provided by Pedersen et al. (1990). In an isozyme analysis of known cultivars of hexaploid wheat, the authors observed an unexpected staining intensity in Pgi isozymes that produced known subunit composition of polypeptides. In their study, a known decreased production of a polypeptide chain was not accompanied by the expected lower staining intensity. Furthermore, certain bands stained more intensely than predicted given a 1:1 model. Similarly, Weeden \& Lamb (1985) noted skewed staining intensity for homodimeric allozymes in some systems but not in others in triploid apple cultivars, thereby suggesting that there was no visual means of detecting which allozyme had the second dose in the latter.

Stebbins (1950) emphasized that no single criterion can be used to determine whether a given polyploid is an autopolyploid or an allopolyploid. Cytological studies have favoured an autoalloploid origin for Coast redwood (Stebbins, 1948; Saylor \& Simons, 1970). Further evidence concerning the origin of polyploidy in this species might be provided by segregation analysis and number of isozymes observed. The expected genetic consequence of strict autopolyploidy is polysomic inheritance, whereas those of strict allopolyploidy are disomic inheritance and fixed heterozygosity. These expectations are well documented. Examples include the observation of tetrasomic inheritance in the autotetraploids Medicago (Quiros, 1982) and Tolmiea menziesii (Soltis \& Rieseberg, 1986), and disomic inheritance in the recently originated allotetraploids, Tragopogon mirus and T. miscellus (Roose \& Gottlieb, 1976).

The observed megagametophytes and their frequencies, being consistent with a model of hexasomic chromosomal segregation, agree with the expected consequences of either an autoallopolyploid or autopolyploid system. Furthermore, the observations clearly preclude disomic inheritance. A strict autohexaploid origin is unlikely as autopolyploidy produces a $2 x-4 x-8 x \ldots$ series. A polyploid species of allopolyploid origin could be expected to show increased numbers of isozyme loci or allozymes (as compared with the diploid parental species or other species with the same ploidy level but of autopolyploid origin). There was no evidence in this study of above-normal numbers of isozyme loci or allozymes. However, as pointed out by Soltis \& Soltis (1990), an increase in number would only be expected if the parental species had divergent forms of the enzymes (otherwise, the duplicated genes would not be detectable as divergent isozymes on starch gels).

The modest conclusion must be that this study of allozyme inheritance offers additional evidence supporting some role of autopolyploidy in the origin of $S$. sempervirens, and precludes a strictly allopolyploid origin. The genetic data are, in fact, consistent both with the karyotype interpretation (Saylor \& Simons, 1970) and the observation made by Stebbins nearly half a century ago, that $S$. sempervirens 'is either an autoallopolyploid with the genomic formula $\mathrm{AAAABB}$, or a segmental allopolyploid with either $A_{1} A_{1} A_{1} A_{1} A_{2} A_{2}$ or $A_{1} A_{1} A_{2} A_{2} A_{3} A_{3}$ ' (Stebbins, 1948).

\section{Acknowledgements}

I gratefully acknowledge the intellectual contributions of two anonymous reviewers. Dr Philip Spieth generously engaged in discussions valuable to this manuscript. Drs David Neale, Constance Millar, and William Libby provided much-appreciated comments that improved the manuscript. I thank the Simpson Timber Company for providing the pedigreed seeds for this study. 


\section{References}

воE, к. N. 1965. Natural Regeneration in Old-growth Redwood Cuttings. USDA Forest Service Research Note PSW-94. Pacific Southwest Forest and Range Experiment Station, Berkeley, CA.

CONKLE, M. T., HODGSKISS, P. D., NUNNALLY, L. B. AND HUNTER, S. C. 1982. Starch Gel Electrophoresis of Conifer Seeds: A Laboratory Manual. USDA Forest Service General Technical Report PSW-64. Pacific Southwest Forest and Range Experiment Station, Berkeley, CA.

EL-KASSABY, Y. A., SZIKLAI, O. AND YEH, F. C. 1982. Inheritance of allozyme variations in coastal Douglas-fir (Pseudotsuga menziesii var. menziesii). Can. J. Genet. Cytol., 24, 325-335.

FOZDAR, B. S. AND LIBBY, w. J. 1968. Chromosomes of Sequoia sempervirens; 8-Hydroxyquinoline-Castor oil pretreatment for improving preparation. Stain Technol., 43, 97-100.

GODT, M. J. W. AND HAMRICK, J. L. 1993. Genetic diversity and population structure in Tradescantia hirsuticaulis (Commelinaceae). Am. J. Bot., 80, 959-966.

HARRY, D. E. 1986. Inheritance and linkage of isozyme variants in incense cedar. J. Hered., 77, 261-266.

LEWIS, L. 1992. Germinative Capacity of Sequoia sempervirens (D. Don) Endl. Seed from Full-Sibling Crosses. Unpublished report, Humboldt State University.

LIBBy, w. J., McCUTCHAN, B. G. AND MILlaR, C. I. 1981. Inbreeding depression in selfs of redwood. Silvae Genet., 30, 15-25.

MILlar, C. I. 1985. Genetic Studies of Dissimilar Parapatric Populations in Northern Bishop Pine (Pinus muricata). Ph.D. Dissertation, University of California at Berkeley.

MILLAR, C. I. AND MARSHALL, K. A. 1991. Allozyme variation of Port-Orford-Cedar (Chamaecyparis lawsoniana): Implications for genetic conservation. Forest Sci., 37, $1060-1077$.

MOODY, M. E., MUELLER, L. D. AND SOLTIS, D. E. 1993. Genetic variation and random drift in autotetraploid populations. Genetics, 134, 649-657.

MUONA, O., YAZDAN1, R. AND LINDQVIST, G. 1987. Analysis of linkage in Picea abies. Hereditas, 106, 31-36.

NEALE, D. B. AND ADAMS, w. T. 1981. Inheritance of isozyme variants in seed tissues of balsam fir (Abies balsamea). Can. J. Bot., 59, 1285-1291.

OLSON, D. F., JR, ROY, D. F. AND WALTERS, G. A. 1990. Sequoia sempervirens (D. Don) Endl. redwood. In: Burns, R. M. and Honkala, B. H. (eds), Silvics of North America, pp. 541-550. USDA Handbook 654. U.S. Government Printing Office, Washington, DC.

PEDERSEN, S., DUE TUVESSON, I. K. AND BODE ANDERSEN, S.
1990. Polymorphism for aconitase and glucosephosphate isomerase isozymes in hexaploid wheat. Hereditas, $113,1-6$.

PERRY, D. J. AND KNOWLES, P. 1989. Inheritance and linkage relationships of allozymes of eastern white cedar (Thuja occidentalis) in northwestern Ontario. Genome, 32, 245-250.

QUIROS, C. F. 1982. Tetrasomic segregation for multiple alleles in alfalfa. Genetics, 101, 117-127.

Rogers, D. L. 1994. Spatial Patterns of Allozyme Variation and Clonal Structure in Coast Redwood (Sequoia sempervirens). Ph.D. Dissertation, University of California at Berkeley.

RoOse, M. L. AND GotTlieb, L. D. 1976. Genetic and biochemical consequences of polyploidy in Tragopogon. Evolution, 30, 818-830.

SAYLOR, L. C. AND SIMONS, H. A. 1970. Karyology of Sequoia sempervirens: Karyotype and accessory chromosomes. Cytologia, 35, 294-303.

SOLTIS, D. E. AND RIESEBERG, L. H. 1986. Autopolyploidy in Tolmiea menziesii (Saxifragaceae): genetic insights from enzyme electrophoresis. Am. J. Bot., 73, 310-318.

SOLTIS, D. E. AND SOLTIS, P. S. 1990. Isozyme evidence for ancient polyploidy in primitive angiosperms. Syst. Bot., $15,328-337$.

STEBBINS, G. L., JR. 1948. The chromosomes and relationships of Metasequoia and Sequoia. Science, 108, 95-98.

STebBINS, G. L., JR. 1950. Variation and Evolution in Plants. Columbia University Press, New York.

STRAuss, s. H. AND CONKLE, M. T. 1986. Segregation, linkage and diversity of allozymes in knobcone pine. Theor. Appl. Genet., 72, 483-493.

WEEDEN, N. F. AND LAMB, R. C. 1985. Identification of apple cultivars by isozyme phenotypes. J. Am. Soc. Hort. Sci., 110, 509-515.

WEEDEN, N. F. AND WENDEL, J. F. 1989. Genetics of plant isozymes. In: Soltis, D. E. and Soltis, P. S. (eds) Isozymes in Plant Biology, Advances in Plant Sciences Series, vol. 4, pp. 46-72. Dioscorides Press, Portland, OR.

WENDEL, J. F. AND WEEDEN, N. F. 1989. Visualization and interpretation of plant isozymes. In: Soltis, D. E. and Soltis, P. S. (eds) Isozymes in Plant Biology, Advances in Plant Sciences Series, vol. 4, pp. 5-45. Dioscorides Press, Portland, OR.

WERTH, C. R. 1989. The use of isozyme data for inferring ancestry of polyploid pteridophytes. Biochem. Syst. Ecol., 17, 117-130.

XIE, C. Y., DANCIK, B. P. AND YEH, F. C. 1991. Inheritance and linkage of isozymes in Thuja orientalis. J. Hered., 82, 329-334. 